\title{
SESSIONS MIXTES 31 ET 4
}

\section{Held on 24, 25 and 26 August 1967}

Chatrman: H. M. Smith.

SECRETARIES: R.G. Hall and J. Kovalevsky.

INTERPRETER: J. Bonanomi.

\section{DEFINITION OF THE SECOND}

$H$. Barrell presented the recommendation made by the Comité Consultatif pour la Définition de la Seconde (CCDS) for an atomic definition of the second. The recommendation reads as follows:

\section{Recommandation $S-1$}

\section{Le Comité Consultatif pour la Définition de la Seconde}

\section{Récommande}

que la seconde, unité de base du Système International d'Unités, soit définie dans les termes suivants:

La seconde est la durée de 9192631770 périodes de la radiation correspondant à la transition entre les deux niveaux hyperfins de l'état fondamental de l'atome de césium 133,

que la seconde telle qu'elle fut définie par décision du Comité International des Poids et Mesures à sa session de 1956 soit désignée sous le nom de 'seconde des éphémérides'.

$H$. Barrell pointed out that two other recommendations call for further investigations of atomic frequency standards and for joint meetings of representatives of the various international scientific or technical Unions concerned, to study the application of this new definition under the coordination of the Comité International des Poids et Mesures.

$\mathrm{He}$ drew attention to the declaration of the CCDS which develops these points insisting, in particular, on the necessity of maintaining Ephemeris Time.

$W$. Markowitz and N. Stoyko, representatives of the IAU on the CCDS, expressed their accord with this new definition.

$J$. Terrien described the procedure that would be followed before the adoption of the final text of this recommendation by the General Conference of Weights and Measures. The form of the text may be modified to exclude the Ephemeris Second from the International System, but the Conference will not interfere with the astronomical use of Ephemeris Time. The International System is a consistent and limited system and does not exclude other units. Since there will not be a formal abrogation of the ephemeris second, the astronomers should be free to use Ephemeris Time.

W. Markowitz expressed the wish that, in the case of a statement of the General Conference that the ephemeris second is not part of the International System of Units, it should be formally recognized that it remains part of the IAU system of astronomical constants. This suggestion was discussed and it was generally agreed that such a statement should be transmitted to the General Conference.

$W$. Markowitz drafted a resolution concurring with the proposed definition of the second, but pointing out that the ephemeris second is part of the IAU system of astronomical constants. After discussion this resolution was modified and adopted by the commissions. It was later approved by the General Assembly in the following form:

\section{Resolution 1}

Commissions 4 and 31 recommend that the following views and information be transmitted to the General Conference of Weights and Measures. (See Resolution No 5, p. 182.). 
There was more discussion on the third recommendation of the CCDS on the future activity of the Comite International des Poids et Mesures in the application of the new definition. J. Terrien assured the members of the commissions that there would be no modification of the third recommendation of the CCDS, which reads as follows:

\section{Recommandation $S-3$}

Le Comité Consultatif pour la Définition de la Seconde

\section{Récommande}

que le Comité International des Poids et Mesures suscite une réunion comprenant des représentants de diverses organisations telles que Bureau International de l'Heure, Union Astronomique Internationale, Union Géodésique et Géophysique Internationale, Union Radioscientifique Internationale, Union Internationale des Télécommunications (Comité Consultatif International des Radiocommunications), pour étudier les problèmes soulevés par l'application des décisions prises concernant la nouvelle définition de l'unité de temps.

\section{EPHEMERIS TIME}

D.H. Sadler made the following remarks on the various time-scales now available.

The atomic time-scale, that he proposes to call atomic clock time (temps atomique intégré), will be a valuable means of measuring intervals of time and will replace E.T. as the reference in the study of the irregularities of the rotation of the Earth.

The measure of Ephemeris time (and hence A.T.-E.T.) is subject to four kinds of limitations.

a) Limitation of principle: it can be obtained practically only through observations of the Moon.

b) Limitation of physical knowledge: the Sun-Earth-Moon system is not conservative.

c) Limitation of theory: errors in the theory of the motion of the Moon and in the astronomical constants.

d) Limitation of observations: arising in the practice of observing the Moon with respect to the stars, or on the meridian.

L. Essen was not in favour of the expression 'atomic clock time' and doubted whether it will be possible to measure significantly A.T.-E.T. T.C. van Flandern pointed out that this would allow the identification of the tidal friction.

A short spirited discussion of the inherent accuracies of the various time scales followed. G.M.R. Winkler and $J$. Terrien stressed the opinion that both atomic and ephemeris times are physical uniform times. Only the practical precision with which they can be measured is different.

In a later meeting, D.H. Sadler proposed a resolution emphasizing that the new definition of the second does not suppress the necessity of observing U.T. and E.T. This was supported by G.M. Clemence, and after some discussion the resolution was approved by the commission and was subsequently adopted by the IAU General Assembly.

\section{Resolution 2}

(See Resolution No. 5, p. 182).

J. Terrien indicated that the International Committee of Weights and Measures will probably approve such a resolution.

\section{RELATIVISTIC EFFECTS}

G.M. Clemence, in his introductory remarks, stressed the fact that, in the last 10 years, experiments have shown the reality of the slowing of clocks in motion with respect to others (1) as well as in a stronger gravity field (2). However, some attacks on Einstein's theory of general relativity have 
recently been made, for example by R.H. Dicke, who found a minor flattening of the Sun that would suffice to explain part of Mercury's motion of the perihelion. On this point, C.G. McVittie criticized the theory of the Sun's interior used by Dicke and suggested that the observation of the solar disc should be continued during two solar cycles.

G.M. Clemence reported on work with $V$. Szebehely in which they computed the difference between the parameters $t$ and $s$ of the basic formula.

$$
\frac{\mathrm{d} t}{\mathrm{~d} s}=1+\left(\frac{1}{r}-\frac{1}{2 a}\right) \times \frac{2 G M}{c^{2}}
$$

where $a$ is the semi-major axis of the Earth's orbit, $r$ the radius vector, $G M$ is the heliocentric constant of gravitation, and $c$ the speed of light.

They provisionally identified $s$ with the proper time of an orbiting clock and $t$ with Ephemeris Time. They deduced that the time indicated by the clock departs periodically from its mean value by 0.0017 second.

G.C. McVittie commented on this identification which he had also made using the Schrodinger approximation (3).

$N$. Stoyko stressed the importance of measuring A.T.-E.T. regardless of their theoretical significance. He also pointed out that $O$. Costa de Beauregard gave formulae analogous to Clemence in 1957 while Fokker found the same numerical results by numerical integration.

W. H. McCrea commented on the formula giving the relativistic red shift and pointed out that one cannot observe the gravitational potential, but only its gradient. One has:

$$
h v=h v_{\mathrm{o}}\left(1-\frac{M}{r}\right)
$$

$v_{0}$ is observed by an observer linked with the emitter, while $v$ is the frequency at zero potential.

L. Essen recommended an experimental approach to the problem and stressed the difficulty introduced by the fact that the reference frames linked with various clocks are different.

G. Becker commented upon Aoki's and Clemence's formula and wished to modify it, taking into account the presence of the clock on the Earth. He believed that the Moon revolving around the Earth is comparable to an atomic clock and that, therefore, E.T. observed with the Moon should be identical to A.T. and will not present the annual term given by those authors.

$S$. Aoki agreed with this point, but pointed out that Ephemeris Time is being defined with the Sun and, consequently this term is real in the definition. He believes that the theory of the motion of the Sun should include relativistic effects in order to define a truly uniform coordinate time E.T.

$W$. Markowitz pointed out that from a practical point of view it is unlikely we will soon be able to check any annual variation of atomic time. The problem may become important when a precision of $10^{-14}$ is attained in atomic clocks.

M. Missana remarked that in the computation of the effect, it should be noted that in relativity theory, the distances must not be identified with the radius-vectors as in classical mechanics.

In a written contribution which arrived too late for presentation at the meeting, R.H. Dicke deduced a variation of the rate of an atomic clock of $6.6 \times 10^{-10}$ (total increase in clock rate from winter to summer).

\section{References}

1. Frische, D. H., Smith, J.H. $\quad$ 1963, Am. J. Phys. 31, 322.

2. Pound, R.V., Rybka, G.A. 1960, Phys. Rev. Lett. 4, 337.

3. McVittie, G.C. 1932, Mon. Not. R. astr. Soc 92, 868.

IV. COORDINATED UNIVERSAL TIME

G.M.R. Winkler put forward a proposal to increase the tolerance of the representation of UT2 by UTC to $300 \mathrm{~ms}$ and to authorize the Director of the Bureau International de l'Heure (BIH) to change the frequency off-sets at the beginning of any month. 
H.M. Smith recalled that two systems of coordinated time exist: the one of the BIH and the one in use in the USSR. They are similar in principle.

D. Belocerkovskij confirmed that the coordination with the BIH in frequency will continue, but that the maximum tolerance in UT2-UTC is limited to 50 milliseconds.

G.M.R. Winkler stated that he would withdraw his proposal if the present systems of the BIH were adopted universally.

A general discussion on the proposal by Winkler took place. The following points were raised:

The navigators would accept a tolerance of $200 \mathrm{~ms}$ (instead of the present $100 \mathrm{~ms}$ ) but not larger (D.H. Sadler).

No major change in the principles of UTC should be introduced since it has proved useful (H.M. Smith, W. Markowitz, L. Essen).

An increase of the tolerance, as well as the possibility of changing the frequency other than once a year, would facilitate the work of the $\mathrm{BIH}$ and permit less frequent changes (G.M.R. Winkler, B. Guinot, N. Stoyko).

Some improvements in the UTC system appear necessary to satisfy the needs of the highestprecision users (G.M.R. Winkler).

Such changes should be accepted by all users and hence should be referred to UIGG, URSI and CCIR (W. Markowitz).

B. Guinot asked for statements by users on whether they prefer offsets in frequency or steps in time.

The discussion was continued in a subsequent session. After some informal discussions $D$. Belocerkovskij indicated that, if possible, the tolerance of the USSR system will be raised to $100 \mathrm{~ms}$. As a consequence it was decided to stress the desirability of a single uniform system and it was agreed that it was inopportune to propose an increase in the tolerance. B. Guinot proposed the following resolution which was adopted unanimously.

\section{Resolution 3}

L'Union Astronomique Internationale

reconnaissant

(a) la nécessité de la coordination des émission de signaux horaires

(b) la nécessité de réduire le nombre des décalages de fréquence et d'ajustements par sauts recommande

(1) que la coordination des émissions de signaux horaires dans le système appelé 'temps coordonné' (TUC) défini par le CCIR à sa réunion plenière de 1966 (Recommendation 374-1, CCIR Documents of the XIth Plenary Assembly, Oslo 1966, Volume III, p. 281, 282), soit universellement étendue,

(2) que la possibilité d'accroître la tolérance pour la différence TU2-TUC soit étudiée par les organisations concernées.

Two other resolutions, one presented by $N$. and $A$. Stoyko and the other by G.M.R. Winkler were discussed. Their aim was to define and to establish a unique international atomic time scale under the responsibility of the BIH and to encourage national time services to make a broader use of atomic frequency standards in order to build local time scales.

B. Guinot indicated that the BIH had experience in constructing an atomic time scale (A.3) by integration and that this technique gives rise to errors due to the instability of the standards. It is therefore necessary to compare as many time scales as possible. These time scales should be based on counts and their origin should not be linked to a given phenomenon such as an epoch in U.T.

After discussion the final wording of the resolutions was presented and adopted. 


\section{Commissions 4 et 31 recommandent}

\section{Resolution 4}

1. l'établissement d'une échelle du temps atomique en prenant pour fréquence de l'étalon à césium, $9192631770 \mathrm{~Hz}$ et qui soit d'accord approximativement avec le TU2 à 0 Heure 1er Janvier 1958 , compte tenu du changement des longitudes conventionnelles,

2. que le BIH coordonne la publication des résultats de la comparaison des horloges atomiques de différents établissements en utilisant le transport des horloges atomiques par avion.

\section{Resolution 5}

Commissions 4 and 31 of the International Astronomical Union recommend:

(i) That the BIH compute an International Atomic Time Scale comprised of independent time scales of the major national time services.

(ii) That this time scale, based on the experiences gained with the experimental scale A3, be computed similarly and published in the form of corrections to the contributing time scales with respect to the international scale.

(iii) That the frequency averaging and integrating as well as time averaging should be used in the computation, but greater weight should be given to time averaging wherever possible.

(iv) That the national time services be encouraged in turn to maintain their time scales independently, based on a broader use of atomic frequency standard resources, and that they also study in cooperation with the BIH the conditions under which different time scales in different countries can be brought into coincidence with that of the BIH.

This resolution was adopted unanimously.

B. Guinot wished to change the name of A.3 to 'International Atomic Time Scale'.

\section{PUBLICATION OF E.T.-U.T.}

$B$. Guinot proposed that values of $\Delta \mathrm{T}$ should be published as soon as they are available. The BIH could centralize and disseminate this information.

$R$. Duncombe indicated that this is done in the Astronomical Ephemeris but believed that it might be done faster by other channels. As far as investigations are concerned, the table of AT-UT2 that is now given in these ephemerides should suffice.

$J$. Kovalevsky stressed the necessity of the centralization and dissemination of partial results obtained in different places by various techniques and $B$. Guinot expressed the belief that such a centralization would encourage new observations, accelerate their transmission and encourage new studies.

$D$. H. Sadler and R. Duncombe thought it would be difficult for one agency to publish observations as the work would be considerable.

It was suggested by H.M. Smith that correspondence between the director of the BIH and other interested organizations on this matter would be useful.

\section{MODIFIED JULIAN DAY}

R.G. Hall and G.M.R. Winkler noted that there is a confusion in the use of Julian Day Number due to a widespread use of various continuous day counts. They suggested a Modified Julian Day number, already in informal use, that equals the Julian day minus 2400000.5 , in addition to the Julian Day Numbers.

Several other propositions were made in order to have a more distinctive name (CDC: continuous day count). $R$. Duncombe objected because of the possible confusion between the two systems. He did not wish to give official notice to this new system. G. Wilkins feared confusion for people using other systems.

No definite opinion of a majority appeared and, after further consideration at subsequent meetings of both commissions, the proposal was rejected. 